\title{
Quantitative analysis of liver function: 3D variable-flip-angle versus Look-Locker T1 relaxometry in hepatocyte-specific contrast-enhanced liver MRI
}

\author{
Niklas Verloh $^{1} \wedge$, Irene Fuhrmann ${ }^{1}$, Claudia Fellner $^{1}$, Dominik Nickel ${ }^{2}$, Florian Zeman ${ }^{3}$, Arne Kandulski ${ }^{4}$, \\ Matthias Hornung ${ }^{5}$, Christian Stroszczynski ${ }^{1}$, Philipp Wiggermann ${ }^{6}$, Michael Haimerl ${ }^{1}$ \\ ${ }^{1}$ Department of Radiology, University Hospital Regensburg, Regensburg, Germany; ${ }^{2} \mathrm{MR}$ Applications Predevelopment, Siemens Healthineers, \\ Erlangen, Germany; ${ }^{3}$ Center for Clinical Trials, University Hospital Regensburg, Regensburg, Germany; ${ }^{4}$ Department of Internal Medicine \\ I, University Hospital Regensburg, Regensburg, Germany; ${ }^{5}$ Department of Surgery, University Hospital Regensburg, Regensburg, Germany; \\ ${ }^{6}$ Department of Radiology, Hospital Braunschweig, Braunschweig, Germany
}

Contributions: (I) Conception and design: N Verloh, M Hornung, P Wiggermann; (II) Administrative support: C Stroszczynski, P Wiggermann; (III) Provision of study materials or patients: I Fuhrmann, A Kandulski, M Hornung; (IV) Collection and assembly of data: N Verloh, I Fuhrmann; (V) Data analysis and interpretation: C Fellner, F Zeman, D Nickel; (VI) Manuscript writing: All authors; (VII) Final approval of manuscript: All authors.

Correspondence to: Niklas Verloh, MD. Department of Radiology, University Hospital Regensburg, 93042 Regensburg, Germany.

Email: niklas.verloh@ukr.de.

Background: Gd-EOB-DTPA, a liver specific contrast agent with T1- shortening effects, is routinely used in clinical magnetic resonance imaging (MRI) for detection and characterization of focal liver lesions. Gd-EOB-DTPA-enhanced T1 relaxometry has recently received increasing attention as a tool for the quantitative analyses of liver function. However, this T1 relaxometry technique is limited due to various artifacts caused by B1 inhomogeneities and motion artifacts. This study aims to compare two different T1 relaxometry techniques for evaluating liver function as determined using a ${ }^{13} \mathrm{C}$-methacetin-based breath test $\left({ }^{13} \mathrm{C}-\mathrm{MBT}\right)$.

Methods: Ninety-six patients underwent gadoxetic acid-enhanced MRI of the liver at $3 \mathrm{~T}$ and a ${ }^{13} \mathrm{C}-\mathrm{MBT}$. Two different prototype sequences for T1 relaxometry were used, a 3D VIBE sequence using Dixon waterfat separation and variable-flip-angles (VFA), as well as a 2D Look-Locker sequence (LL). Images were acquired before (T1 pre) and 20 minutes after (T1 post) administration of liver-specific contrast agent to evaluate the reduction rates of T1 relaxation time (rrT1) in accordance with the ${ }^{13} \mathrm{C}-\mathrm{MBT}$ outcome. To analyze both MR sequences' performance, the intraclass correlation coefficient (ICC) between four ROI measurements within the same liver and the coefficient of repeatability (CR) were calculated.

Results: T1 relaxometry measurements based on MR sequences, VFA, and LL show a constant change in line with impaired liver function progression. Simple regression models showed a log-linear correlation of ${ }^{13}$ C-MBT values with all evaluated T1 relaxometry measurements (VFA T1post, VFA rrT1, LL T1post, LL rrT1, P<0.001). Both ICC (VFA T1post, LL T1post; 0.75, 0.95) and CR (VFA T1 post, LL T1 post; 179, 101) showed a better agreement between ROI measurements using the LL sequence.

Conclusions: Both T1 relaxometry sequences are suitable for the evaluation of liver function based on ${ }^{13} \mathrm{C}$-MBT. However, the Look-Locker sequence is less susceptible to artifacts and might be more advantageous, especially in patients with impaired liver function.

Keywords: Liver; magnetic resonance imaging (MRI); gadolinium DTPA; T1 quantification

\footnotetext{
^ ORCID: 0000-0002-8424-5827.
} 
Submitted Jul 03, 2021. Accepted for publication Nov 12, 2021.

doi: 10.21037/qims-21-597

View this article at: https://dx.doi.org/10.21037/qims-21-597

\section{Introduction}

In clinical routine, contrast-enhanced magnetic resonance imaging (MRI) is a highly standardized method to visualize liver architecture and parenchyma. Among available contrast agents, the liver-specific gadoxetic acid (Gd-EOB-DTPA) is used as a hepatobiliary agent for T1-weighted imaging (1). While Gd-EOB-DTPA was initially used for detection and characterization of different liver lesions $(2,3)$, GdEOB-DTPA-enhanced MRI has been recently evolved into a promising approach to assess liver function $(4,5)$ or to stage liver fibrosis $(6,7)$. Due to its liver-specific character, Gd-EOB-DTPA enters the hepatocytes via organic anion transporters OATP1B1/B3 and is subsequently biliary excreted at the canalicular membrane by MRP2 transporters (8-10). The parenchymal accumulation enables the evaluation of signal intensities (SI) and, due to the paramagnetic properties of the gadolinium ion, the longitudinal T1 relaxation time is shortened. This characteristic paramagnetic feature of Gd-EOB-DTPA allows the measurement of the $\mathrm{T} 1$ relaxation time in the investigated tissue, providing absolute values in milliseconds (ms).

Both methods, SI measurement, and T1 relaxometry have been shown to assess liver function reliably, but still, the T1 relaxometry bears a few decisive advantages and may even be considered superior to SI $(5,11)$. The SI measurement is influenced by various technical parameters, such as the radiofrequency amplifiers or the receiver coils; therefore, a direct comparison of values between individual patients, examinations, or between different MR machines is impossible $(12,13)$. The potential application of $\mathrm{T} 1$ relaxometry regarding the evaluation of liver function has been demonstrated by significant correlation of T1 relaxation times and established liver function tests and scores, such as the Child-Pugh Score $(13,14)$, the MELD Score (15) and the ICG clearance test $(16,17)$. Two different approaches are applied in our study for T1 relaxometry: T1 mapping with the variable-flip-angle (VFA) techniques is using a $3 \mathrm{D}$ gradient echo sequence with different flip angles to generate color-coded T1 maps. This sequence type offers a high spatial resolution and is commonly used for volumetric approaches. Due to a short repetition time (TR), this method needs less acquisition time than conventional T1 mapping methods. Critical is the substantial impact of RF field inhomogeneities, which are reduced by the additional acquisition of a B1 field map (18). The Look-Locker sequence (LL), initially published in 1970 (19), is based on an inversion recovery method which acquires multiple data points during a single inversion time (TI). An initial inversion pulse is followed by multiple, rapidly applied low flip angle readout pulses, creating a set of gradient echoes (20). We compared the data of these two different prototype sequences for $\mathrm{T} 1$ relaxometry with the liver function as assessed by ${ }^{13} \mathrm{C}$-methacetin breath test $\left({ }^{13} \mathrm{C}-\mathrm{MBT}\right)(21)$, which is considered to be a gold standard for the evaluation of liver function. This study aimed to compare the performance of two different T1 relaxometry techniques, using a 3D VIBE sequence with VFA and Dixon water-fat separation and a novel prototype 2D Look-Locker (LL) sequence for the evaluation of liver function.

We present the following article in accordance with the MDAR checklist (available at https://qims.amegroups.com/ article/view/10.21037/qims-21-597/rc).

\section{Methods}

\section{Patients}

The study was approved by institutional ethics board of the University Hospital Regensburg (No. 16-1010177) and informed consent was taken from all individual participants. The study was conducted in accordance with the Declaration of Helsinki (as revised in 2013). Ninety-six patients (74 men, 22 women, age range 39-82 years) underwent ${ }^{13} \mathrm{C}-\mathrm{MBT}$ to evaluate liver function and Gd-EOB-DTPA-enhanced MRI at 3 Tesla with both a prototype $3 \mathrm{D}$ VFA sequence and a prototype $2 \mathrm{D}$ Look-Locker sequence. Indications for liver imaging were suspicion for chronic liver disease or focal hepatic lesions, active hepatocellular carcinoma (HCC) or HCC surveillance, follow-up in case of known secondary malignancies, as well as pre- and post-interventional assessment. Detailed information about included tumor entities is given in Table 1. Exclusion criteria were implants not suitable for MRI, impaired renal function, previous allergic reaction to MR contrast media, paracetamol, or its derivatives. 
Table 1 Reasons for MRI and the corresponding underlying diseases

\begin{tabular}{|c|c|c|c|c|c|}
\hline Underlying medical condition & $\begin{array}{c}\text { Active } \\
\text { hepatocellular } \\
\text { carcinoma } \\
\text { monitoring }(n=28)\end{array}$ & $\begin{array}{l}\text { Follow-up in case } \\
\text { of known secondary } \\
\text { malignancies } \\
(n=19)\end{array}$ & $\begin{array}{l}\text { Preinterventional } \\
\text { assessment } \\
(n=12)\end{array}$ & $\begin{array}{l}\text { Postinterventional } \\
\text { assessment } \\
(n=22)\end{array}$ & $\begin{array}{l}\text { Suspected liver } \\
\text { disease or focal } \\
\text { hepatic lesions } \\
(n=15)\end{array}$ \\
\hline Alcoholic liver disease & 13 & 4 & 3 & 3 & 6 \\
\hline Type B viral cirrhosis & 2 & & & 5 & \\
\hline Cryptogenic cirrhosis & 2 & & & 3 & \\
\hline Nash & 6 & 1 & & 2 & 3 \\
\hline No known underlying liver disease & & 14 & 7 & 8 & 5 \\
\hline \multicolumn{6}{|l|}{ Benign liver lesion } \\
\hline $\mathrm{HCC}$ w/ cirrhosis & 28 & & 5 & 17 & 5 \\
\hline HCC w/o cirrhosis & & & & & 1 \\
\hline Cholangiocarcinoma & & 4 & 2 & 2 & 1 \\
\hline \multicolumn{6}{|l|}{ Secondary malignancies } \\
\hline Thymoma & & 1 & & & \\
\hline Duodenal carcinoma & & 1 & & & \\
\hline Neuroendocrine tumor of the ileum & & 1 & & & \\
\hline Colorectal carcinoma & & 9 & 4 & 2 & 1 \\
\hline
\end{tabular}

Other: Overlap Syndrome (autoimmune hepatitis and primary biliary cirrhosis). MRI, magnetic resonance imaging; HCC, hepatocellular carcinoma.

\section{${ }^{13}$ C-methacetin breath test}

$\mathrm{A}^{13} \mathrm{C}$-methacetin breath test to assess liver function (LiMAx - maximum liver function capacity test) was performed before or after MRI within a timeframe of $24 \mathrm{~h}$. After fasting for at least $3 \mathrm{~h}$, the baseline ${ }^{13} \mathrm{CO}_{2}{ }^{12} \mathrm{CO}_{2}$ ratio in the exhaled breath was measured using modified nondispersive isotope-selective infrared spectroscopy (FANci2-db16, Fischer Analysen Instrumente, Leipzig, Germany). Ten minutes later, $2 \mathrm{mg} / \mathrm{kg}$ body weight ${ }^{13} \mathrm{C}$-methacetin followed by $20 \mathrm{~mL} 0.9 \% \mathrm{NaCl}$ was administered by intravenous bolus injection. Subsequently, the dynamic of the ${ }^{13} \mathrm{CO}_{2}$ production was measured in real-time for 60 minutes. Results are given in $[\mu \mathrm{g} / \mathrm{kg} / \mathrm{h}]$.

According to the best achieved ${ }^{13} \mathrm{C}-\mathrm{MBT}$ readouts, the patients were grouped into three categories as proposed by Stockmann et al. (22). Category 1 is representing normal liver function $\left({ }^{13} \mathrm{C}-\mathrm{MBT}>315 \mu \mathrm{g} / \mathrm{kg} / \mathrm{h}\right)$, category 2 intermediate liver function $\left({ }^{13} \mathrm{C}-\mathrm{MBT} 140-315 \mu \mathrm{g} / \mathrm{kg} / \mathrm{h}\right)$, and category 3 heavily impaired liver function $\left({ }^{13} \mathrm{C}-\mathrm{MBT}\right.$ $<140 \mu \mathrm{g} / \mathrm{kg} / \mathrm{h})$.

\section{MRI}

MRI was performed with a clinical whole-body $3 \mathrm{~T}$ system 
(MAGNETOM Skyra, Siemens Healthineers, Erlangen, Germany). For signal reception, a combination of body and spine array coil elements of an 18-channel body and a 32-channel spine matrix coil was used.

In addition to the routine imaging protocol, $\mathrm{T} 1$ relaxometry of the liver was performed prior to (non-contrast) and 20 minutes after the intravenous administration of the contrast. Gd-EOB-DTPA (Primovist; Bayer Healthcare, Berlin, Germany) was administered as a bolus injection at a flow rate of $1 \mathrm{ml} / \mathrm{s}$ and flushed with $20 \mathrm{~mL}$ of $0.9 \% \mathrm{NaCl}$.

Color-coded T1 maps were calculated inline for two different relaxometry approaches. First, for VFA technique, a $3 \mathrm{D}$ VIBE sequence with variable flip angles using Dixon water-fat separation $(\mathrm{TR}=5.79 \mathrm{~ms}$, TE $1=2.46 \mathrm{~ms}$; TE 2 $=3.69 \mathrm{~ms}$; flip angles $1^{\circ}, 7^{\circ}, 14^{\circ}$; measured voxel size, $3.6 \mathrm{~mm}$ $\times 2.5 \mathrm{~mm} \times 4.7 \mathrm{~mm}$, reconstructed to $2.5 \mathrm{~mm} \times 2.5 \mathrm{~mm} \times 3.0$ $\mathrm{mm}, 72$ slices; acquisition time $17 \mathrm{sec}$ ) and CAIPIRINHA (Controlled Aliasing In Parallel Imaging Results in Higher Acceleration) with an acceleration factor of 4 as a parallel imaging technique was applied within a single breath-hold. Prior to the T1 relaxometry measurements, a B1 map of the whole liver was acquired and inline corrected to improve these T1 maps' homogeneity (23). The implementation relies on the assumption that for the VFA acquisitions the actual flip angle at a given voxel differs from the nominal flip angle specified in the measurement protocol by the same factor as the B1 map from the nominal B1 and allows to use corrected flip angles in the FLASH signal model during the estimation of T1 values (24). Further a single breath-hold Look-Locker based 2D FLASH sequence ( TR $=3.0 \mathrm{~ms}$, TE $=1.32 \mathrm{~ms}$, flip angle $8^{\circ}$; measured voxel size $3.0 \mathrm{~mm} \times 2.1 \mathrm{~mm} \times 8.0 \mathrm{~mm}$, reconstructed voxel size $2.1 \mathrm{~mm} \times 2.1 \mathrm{~mm} \times 8.0 \mathrm{~mm}, 3$ slices acquisition time $16 \mathrm{sec}$ ) was implemented. The sequence acquires the data for a single slice using non-selective inversion followed by continuous FLASH acquisitions of 16 contrasts with a temporal resolution of $201 \mathrm{~ms}$. For the free recovery of the longitudinal magnetization a dead time of 2 seconds is introduced after sampling of a relaxation curve (25).

\section{Image analysis}

T1 relaxation times were measured using operator-defined regions of interest (ROIs) analysis before and after GdEOB-DTPA-administration. Four ROIs were placed manually in the T1 maps ( 3 in the right lobe, 1 in the left lobe) at the MR scanner workstation, excluding visible vessels, focal solid liver lesions. The circular ROIs were chosen to be as large as possible, placed at identical locations in the different sequences, and corrected depending on patient movement.

The mean T1 values for the 4 ROIs were considered as the representative $\mathrm{T} 1$ values of the entire liver. The $\mathrm{T} 1$ relaxation times were calculated for each patient, and the reduction rate of $\mathrm{T} 1$ relaxation time ( $\mathrm{rrT} 1)$ was calculated for both VFA MR data (VFA rrT1) and the Look-lockerbased data (LL rrT1):

$$
\begin{aligned}
& \text { reduction rate of } T 1 \text { relaxation time }(\text { rrT } 1) \\
& =\left\lfloor\frac{T 1 \text { pre }-T 1 \text { post }}{T 1 \text { pre }}\right\rfloor \times 100(\%)
\end{aligned}
$$

\section{Statistical analysis}

Statistical analysis was performed using IBM SPSS Statistics (version 26, Chicago, IL, USA) and R 4.0.4 (R Foundation for Statistical Computing, Vienna, Austria). All tests were two-sided, and the statistical significance level was set to 0.05 . All data are given as mean \pm standard deviation.

The non-parametric Kruskal-Wallis test with post-hoc pairwise comparison and Bonferroni adjustment (DunnBonferroni-Tests) was used to analyze differences between the three patient groups as stratified by the categories of ${ }^{13} \mathrm{C}-\mathrm{MBT}$ readout regarding the patient characteristics.

Simple linear regression models were calculated to assess the predictive power of Gd-EOB-DTPA-enhanced T1-relaxometry measurements ( $\mathrm{T} 1$ pre, $\mathrm{T} 1$ post) and the reduction rate of the $\mathrm{T} 1$ relaxation times ( $\mathrm{rrT} 1)$ before and 20 min after Gd-EOB-DTPA administration to ${ }^{13} \mathrm{C}-\mathrm{MBT}$ readout values. The optimal curve fit was assessed visually and by using the coefficient of correlation $r$.

To further compare both MRI sequences' performance, we analyzed the homogeneity of the T1 relaxation time measurements across four individual ROIs of each patient. The repeatability of the ROI measurement based on the LL and VFA sequence was assessed by determining the intraclass correlation coefficient (ICC). This was calculated as a twoway mixed model measuring the absolute agreement. Further, a Bland-Altman plot was generated, and the repeatability coefficient (CR) was calculated. The CR is defined as the value below which the absolute differences between two measurements would lie with a probability of 0.95 .

\section{Data availability}

The data that support the findings of this study are available 
Table 2 Patient characteristics

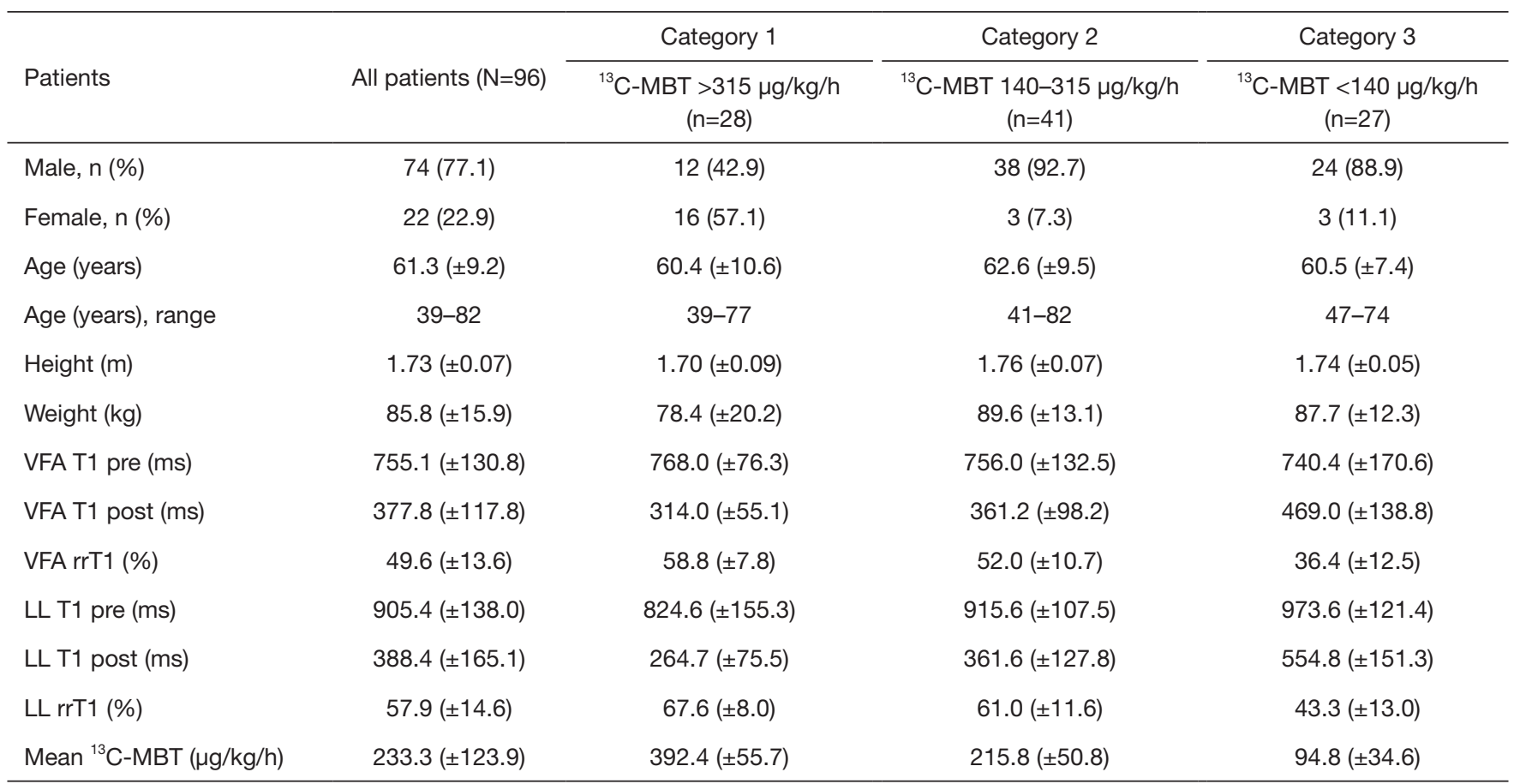

Values indicate the mean \pm standard deviation. T1 pre: native T1 relaxation time before Gd-EOB-DTPA administration. T1 post: T1 relaxation time $20 \mathrm{~min}$ after Gd-EOB-DTPA administration. rrT1, reduction rate of $\mathrm{T} 1$ relaxation time; VFA, variable-flip-angle; LL, Look-Locker; ${ }^{13} \mathrm{C}-\mathrm{MBT},{ }^{13} \mathrm{C}$-methacetin breath test.

within the article.

\section{Results}

In total, 96 patients (74 men, 22 women; mean age 63.1; range, 39-82 years) were included in this study. Underlying diseases and detailed patient characteristics are given in Table 1 and Table 2.

Patients were divided into three groups according to the ${ }^{13} \mathrm{C}-\mathrm{MBT}$ values. There was no significant difference in VFA $\mathrm{T} 1$ pre between the three groups, while $\mathrm{T} 1$ pre values of LL were significantly lower in group 1 compared to group $2(\mathrm{P}=0.003)$ and $3(\mathrm{P}=0.001)$. The $\mathrm{T} 1$ post measurements of group 3 of the VFA group were significantly higher than of group $1(\mathrm{P}<0.001)$ and group $2(\mathrm{P}=0.002)$. In the LL group, the measurements of $\mathrm{T} 1$ post were significantly different between all three groups $(\mathrm{P}<0.01$, Figure 1$)$.

Both VFA- and LL-based T1 relaxometry data were analyzed in a simple linear regression analysis to determine the predictive power of relaxometry values on ${ }^{13} \mathrm{C}-\mathrm{MBT}$ readouts. The correlation of the $\mathrm{T} 1$ relaxation time $20 \mathrm{~min}$ after Gd-EOB-DTPA administration (T1 post) and the reduction rate of $\mathrm{T} 1$ relaxation time (rrT1) with ${ }^{13} \mathrm{C}-\mathrm{MBT}$ values were investigated. The optimal curve fit for ${ }^{13} \mathrm{C}-\mathrm{MBT}$ was a log-linear relationship with $\mathrm{r}=0.590$ for VFA T1 post and $\mathrm{r}=0.724$ for LL $\mathrm{T} 1$ post. The reduction rates of $\mathrm{T} 1$ relaxation time showed higher correlation coefficients than the respective $\mathrm{T} 1$ post values: $\mathrm{r}=0.706$ for VFA $\mathrm{rrT} 1$ and r=0.727 for LL rrT1 (Table 3, Figure 2).

Representative examples of the liver function dependent MRI are given in Figure 3-5. The male patient (66 years old) in Figure 3 was classified with normal liver function due to the achieved maximal ${ }^{13} \mathrm{C}-\mathrm{MBT}$ readout value of $380 \mu \mathrm{g} / \mathrm{kg} / \mathrm{h}$. Based on the corresponding T1 maps, a VFA rrT1 of $62 \%$ and LL rrT1 $68 \%$ was determined. In contrast, Figure 4 displays a male patient (71 years old) with impaired liver function $(111 \mu \mathrm{g} / \mathrm{kg} / \mathrm{h}), \mathrm{VFA} \operatorname{rrT} 1$ of $48 \%$ and LL rrT1 41\%, and Figure 5 displays a male patient (60 years old) with pronounced ascites, impaired liver function $(120 \mu \mathrm{g} / \mathrm{kg} / \mathrm{h}), \mathrm{VFA} \operatorname{rrT} 1$ of $46 \%$ and LL $\operatorname{rrT} 1$ of $48 \%$. In all cases, an increase in hepatic details can be observed in Look-Locker based MRI compared to VFA-based T1 maps, as shown in the exemplary images (Figures 3-5). 

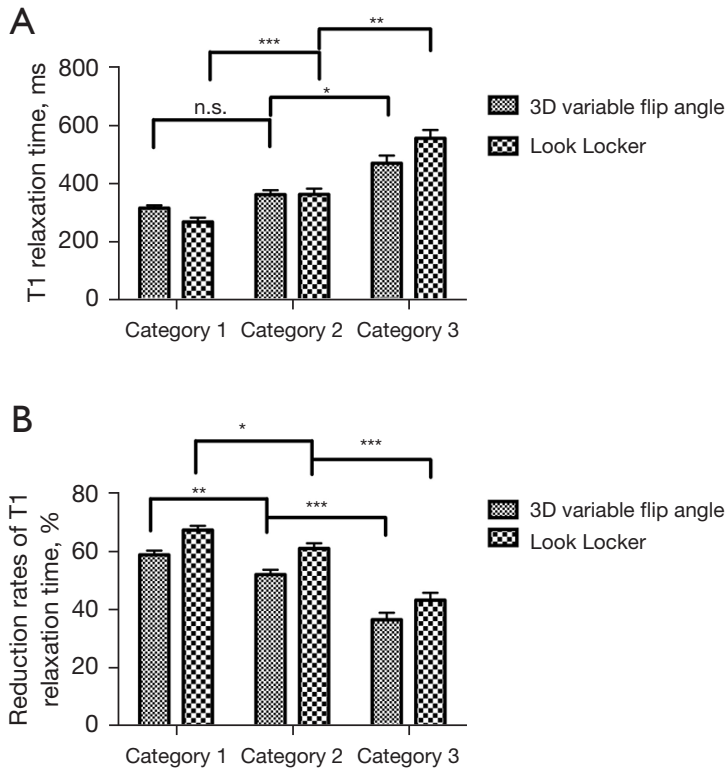

Figure $1 \mathrm{~T} 1$ relaxometry measurements stratified by ${ }^{13} \mathrm{C}-\mathrm{MBT}$ categories. Comparison of T1 relaxometry measurements using two different MR sequences, a variable-flip-angle (VFA) sequence, and a Look-Locker-based (LL) sequence. (A) T1 relaxation time 20 min after administration of the contrast agent Gd-EOB-DTPA. (B) Reduction rates of T1 relaxation time (rrT1) stratified by ${ }^{13} \mathrm{C}-\mathrm{MBT}\left({ }^{13} \mathrm{C}\right.$-methacetin-based breath test) readouts ***, $\mathrm{P}<0.001$; **, $\mathrm{P}<0.01$; *, $\mathrm{P}<0.05$; n.s., non-significant (Dunn-BonferroniTests).

To further compare both MRI sequences' performance, we analyzed the intra-liver variation of the $\mathrm{T} 1$ relaxation time measurements across four individual ROIs of each patient. For this analysis, we compared native and postcontrast T1 maps acquired with the T1_LL and T1_VFA sequences, respectively. The ICC was higher in both pre and post T1_LL sequences $(\mathrm{LL}$ T1 pre $=0.88$, LL T1 post $=0.95)$ compared to the ICC in the T1_VFA sequences (VFA $\mathrm{T} 1$ pre $=0.58$, VFA T1 post $=0.75)$. The CR of the T1 LL sequence was smaller than the CR of the VFA-derived measurements. This refers to both pre-contrast T1 maps (LL T1 pre =137; VFA T1 pre =270) and Gd-EOB-DTPAenhanced T1 maps (LL T1 post $=101$; VFA T1 post $=179$, Table 4, Figure 6).
Table 3 Simple linear regression models of T1 relaxation measurements on ${ }^{13} \mathrm{C}-\mathrm{MBT}$ values

\begin{tabular}{lccc}
\hline T1 relaxation time & $\mathrm{B}(95 \% \mathrm{Cl})$ & $\mathrm{P}$ value & $\mathrm{r}$ \\
\hline Log $\left({ }^{13} \mathrm{C}-\mathrm{MBT}\right)$ & & & \\
VFA T1 post & $-0.001(-0.002 ;-0.001)$ & $<0.001$ & 0.590 \\
VFA rrT1 & $0.014(0.011 ; 0.017)$ & $<0.001$ & 0.706 \\
LL T1 post & $-0.001(-0.001 ;-0.001)$ & $<0.001$ & 0.724 \\
LL rrT1 & $0.014(0.011 ; 0.017)$ & $<0.001$ & 0.727 \\
\hline
\end{tabular}

T1 post, T1 relaxation time 20 min after Gd-EOB-DTPA administration; rrT1, reduction rate of $\mathrm{T} 1$ relaxation time; VFA, variable flip angle; LL, look-locker; ${ }^{13} \mathrm{C}-\mathrm{MBT},{ }^{13} \mathrm{C}$-methacetin breath test; R, multiple correlation coefficient; B, linear regression coefficient; $\mathrm{Cl}$, confidence interval for $\mathrm{B}$.
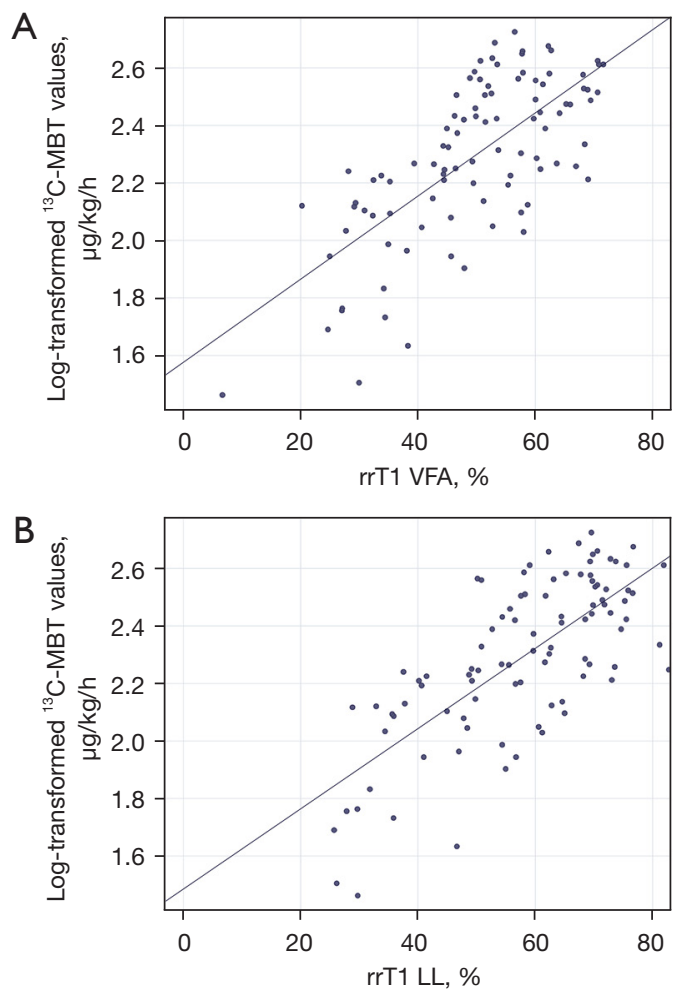

Figure 2 Correlation analysis of the reduction rate of $\mathrm{T} 1$ relaxation time to the ${ }^{13} \mathrm{C}-\mathrm{MBT}$ readout. Scatterplot of the reduction rate of $\mathrm{T} 1$ relaxation time ( $\mathrm{rrT} 1)$ as calculated using a variable-flip-angle (VFA) sequence (A, r=0.706) and a Look-Locker (LL) based sequence (B, r=0.727) on log-transformed ${ }^{13} \mathrm{C}$-MBT $\left({ }^{13} \mathrm{C}\right.$-methacetin-based breath test) values. 

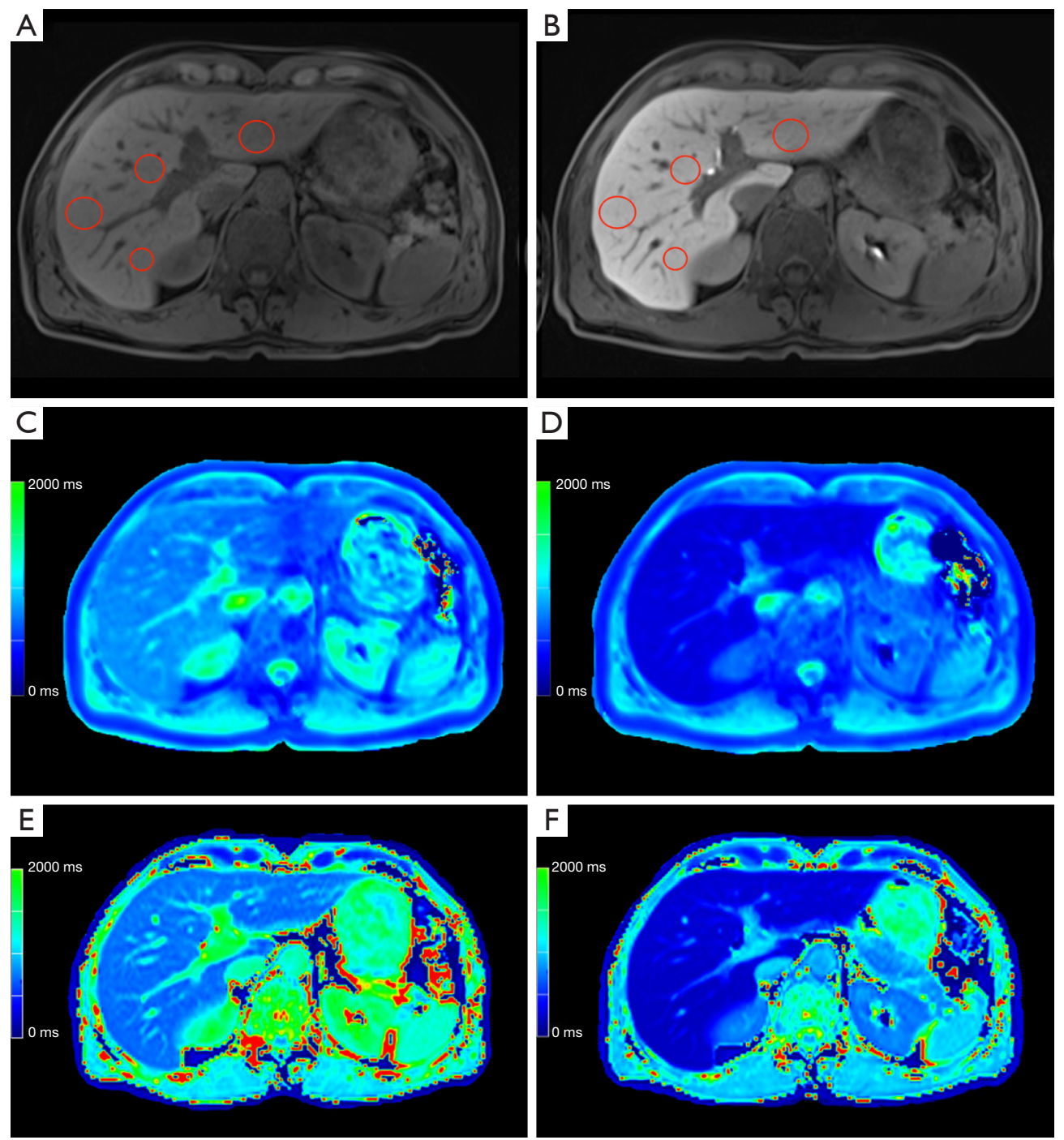

Figure 3 Morphological T1-weighted VIBE sequences and color-coded T1 maps of the liver parenchyma for a patient with normal liver function. Comparison of T1 maps calculated using two different MR sequences, images obtained before (A,C,E) and 20 min after administration of Gd-EOB-DTPA (B,D,F) in a patient with normal liver function $\left(66\right.$ years old male, ${ }^{13} \mathrm{C}-\mathrm{MBT}$ value $=380 \mu \mathrm{gg} / \mathrm{kg} / \mathrm{h}$, LL rrT1 $=68 \%$, VFA rrT1 =62\%). (A) and (B) show T1-weighted VIBE sequences (volume-interpolated breath-hold examination, fatsaturated, TR =3.09 ms, TE $=1.17 \mathrm{~ms}, 10^{\circ}$ flip angle). (C) (mean VFA T1 pre $=741.8 \mathrm{~ms}$ ) and (D) (mean VFA T1 post =279.0 ms) show T1 maps acquired with a variable-flip-angle (VFA) MR sequence. (E) (mean LL T1 pre =718.3 ms) and (F) (mean LL T1 post =231.8 ms) are indicating respective T1 maps acquired with a Look-Locker-based (LL) MR sequence.

\section{Discussion}

A considerable number of different liver function tests have been established in the clinical routine. This is of particular clinical interest to predict the remnant liver parenchyma's functional metabolic outcome after surgical resections. Here, the ICG clearance test measures the elimination of Indocyanine green (ICG) from the bloodstream $(26,27)$, and the ${ }^{13} \mathrm{C}$-methacetin-based breath test measures the conversion of ${ }^{13} \mathrm{C}$-labelled substrate into ${ }^{13} \mathrm{CO}_{2}(21)$. Patients with diffuse liver disease, such as ICU patients or oncology patients, require an accurate estimate of liver function and patients undergoing major liver resection require an estimate of remnant liver function for optimal treatment planning. Postoperative remnant liver function is 

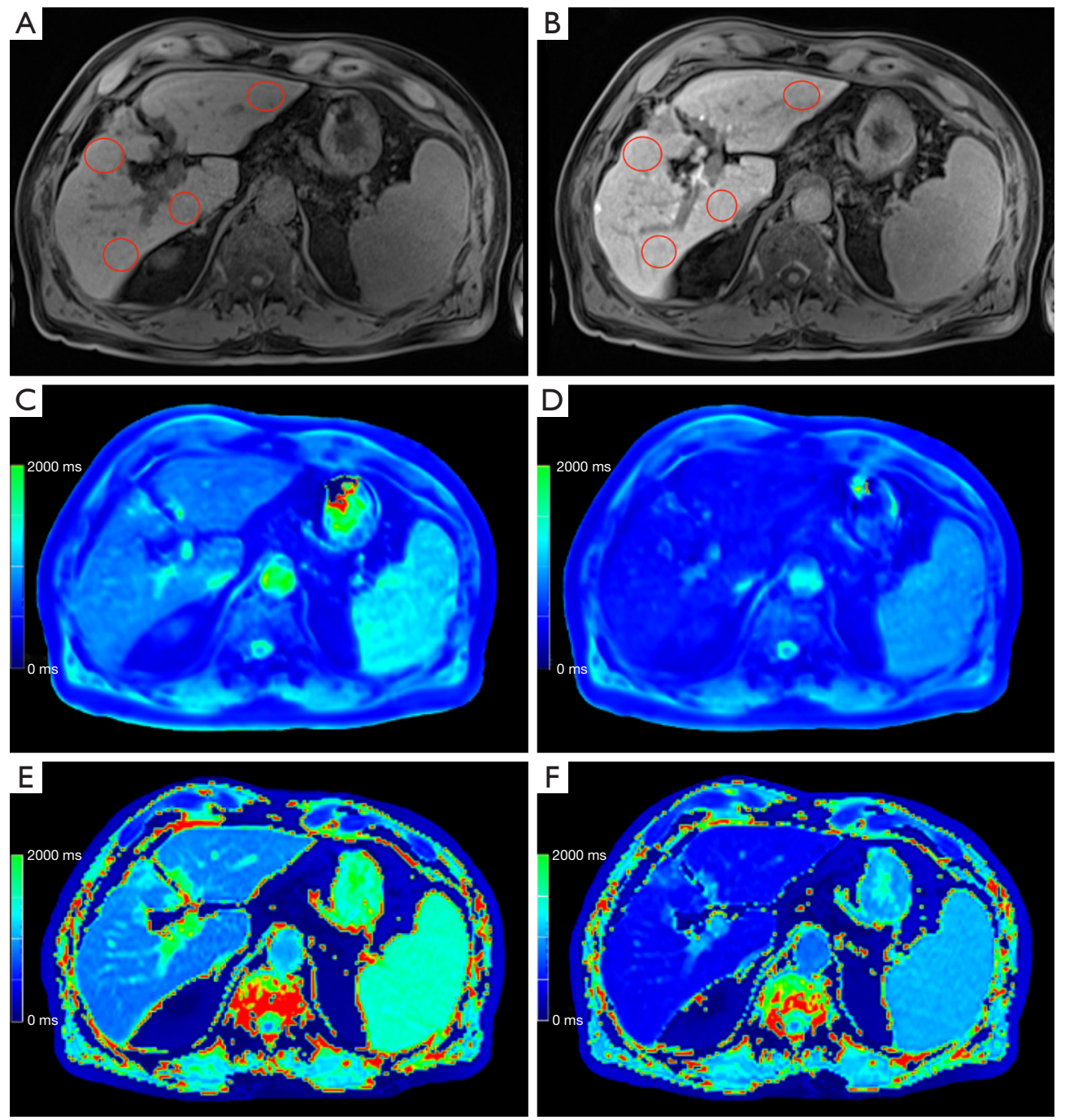

Figure 4 Morphological T1- weighted VIBE sequences and color-coded T1 maps of the liver parenchyma for a patient with impaired liver function. Comparison of T1 maps calculated using two different MR sequences, images obtained before (A,C,E) and 20 min after administration of Gd-EOB-DTPA (B,D,F) in a patient with impaired liver function $\left(71\right.$ years old male, ${ }^{13} \mathrm{C}-\mathrm{MBT}$ value $=111 \mu \mathrm{g} / \mathrm{kg} / \mathrm{h}, \mathrm{VFA}$ $\operatorname{rrT} 1=41 \%$, LL rrT1 =48\%). (A) and (B) show T1-weighted VIBE sequences (volume-interpolated breath-hold examination, fat-saturated, $\mathrm{TR}=3.09 \mathrm{~ms}, \mathrm{TE}=1.17 \mathrm{~ms}, 10^{\circ}$ flip angle). (C) (mean VFA T1 pre $=847.8 \mathrm{~ms}$ ) and (D) (mean VFA T1 post $=503.3 \mathrm{~ms}$ ) show T1 maps acquired with a variable-flip-angle (VFA) MR sequence. (E) (mean LL T1 pre $=857.0 \mathrm{~ms}$ ) and (F) (mean LL T1 post =442.3) are indicating respective T1 maps acquired with a Look-Locker-based (LL) MR sequence.

estimated volumetrically using imaging data from computed tomography (CT) or MRI, while the determination of absolute liver function is currently based primarily on laboratory tests and clinical scores (28). Actual global liver function can be estimated using, for example, the ICG test or the LiMAx test. However, these tests indicate global liver function and are limited when liver function is inhomogeneously distributed. In recent years, MRI using the hepatocyte-specific contrast agent Gd-EOB-DTPA has been shown to be suitable for evaluating liver function as well (29). GD-EOB-DTPA is metabolized similarly to ICG and mebrofenin, while MRI can visualize its distribution in the liver with higher temporal and spatial resolution. Moreover, MRI-based determination of liver function can be integrated into routine preoperative imaging, allowing the evaluation of liver function and provide morphological 

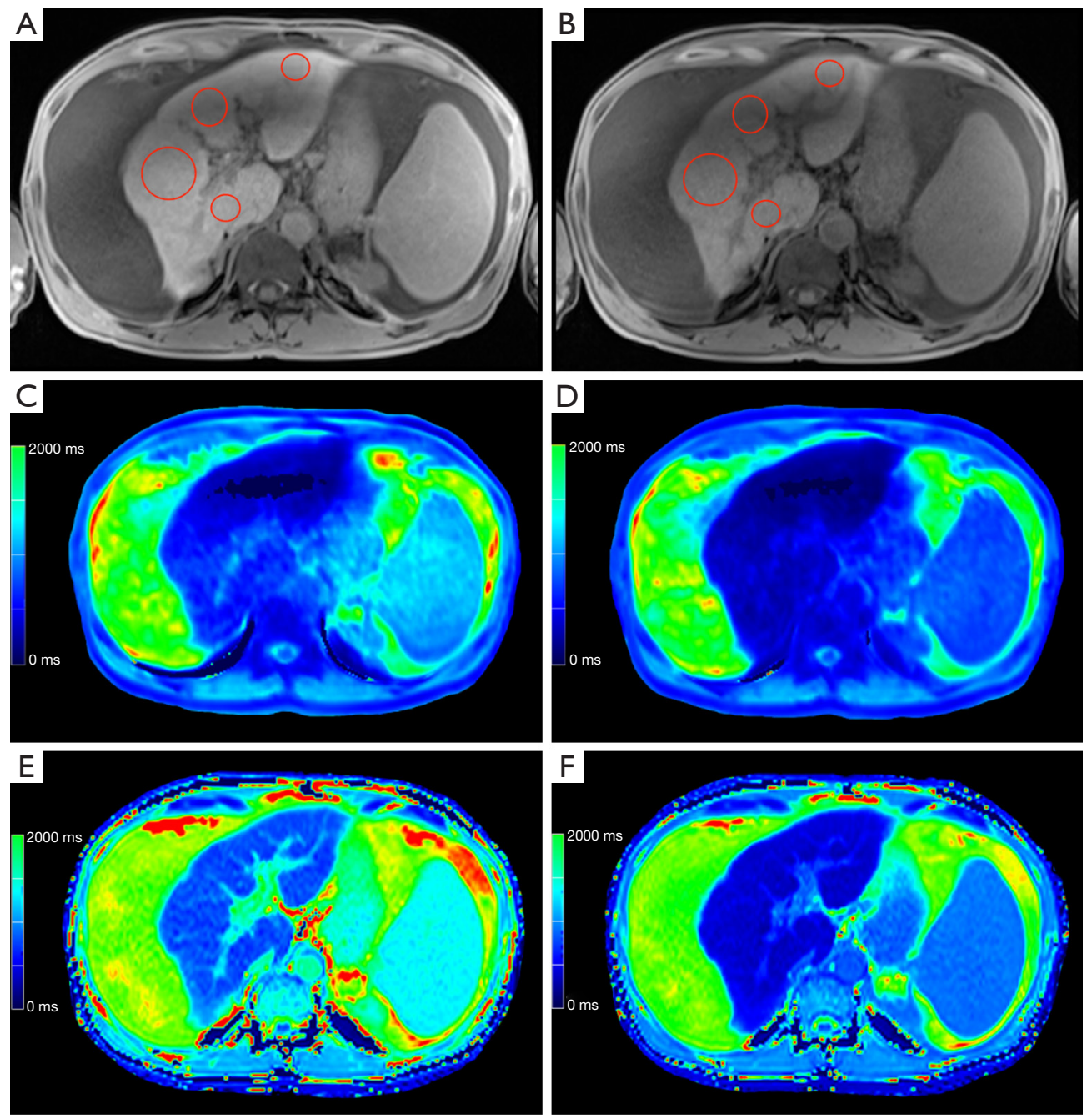

Figure 5 Morphological T1- weighted VIBE sequences and color-coded T1 maps of the liver parenchyma for a patient with ascites. Comparison of T1 maps calculated using two different MR sequences, images obtained before (A,C,E) and 20 min after administration of Gd-EOB-DTPA (B,D,F) in a patient with impaired liver function and pronounced ascites $\left(60\right.$-year-old male, ${ }^{13} \mathrm{C}-\mathrm{MBT}$ value $=120 \mu \mathrm{gg} / \mathrm{kg} / \mathrm{h}$, VFA rrT1 $=46 \%$, LL rrT1 =48\%). A and B show T1-weighted VIBE sequences (volume-interpolated breath-hold examination, fatsaturated, TR $=3.09 \mathrm{~ms}, \mathrm{TE}=1.17 \mathrm{~ms}, 10^{\circ}$ flip angle). (C) (mean VFA T1 pre $=531.0 \mathrm{~ms}$ ) and (D) (mean VFA T1 post =288.8 ms) show T1 maps acquired with a variable-flip-angle (VFA) MR sequence. $(\mathrm{E})$ (mean LL T1 pre $=824.5 \mathrm{~ms})$ and $(\mathrm{F})(\mathrm{mean} \mathrm{LL} \mathrm{T1}$ post $=430.5 \mathrm{~ms})$ are indicating respective T1 maps acquired with a Look-Locker-based (LL) MR sequence.

Table 4 Intraliver variation (homogeneity) of the ROIs for LL and VFA T1 relaxometry

\begin{tabular}{lcccc}
\hline Method & Livers $(\mathrm{n})$ & Measurements 4 ROIS $(\mathrm{n})$ & Intra-CC $(95 \% \mathrm{Cl})$ & $\mathrm{CR}$ \\
\hline LL pre & 96 & 366 & $0.88(0.84,0.91)$ & $0.95(0.93,0.97)$ \\
LL post & 96 & 366 & $0.58(0.49,0.67)$ & 137 \\
VFA pre & 96 & 366 & $0.75(0.68,0.81)$ & 270 \\
VFA post & 96 & 366 & 179 \\
\hline
\end{tabular}

95\% Cl, 95\% confidence interval; Intra-CC, intraclass correlation coefficient; VFA, variable flip angle; LL, look-locker; CR, repeatability coefficient. 

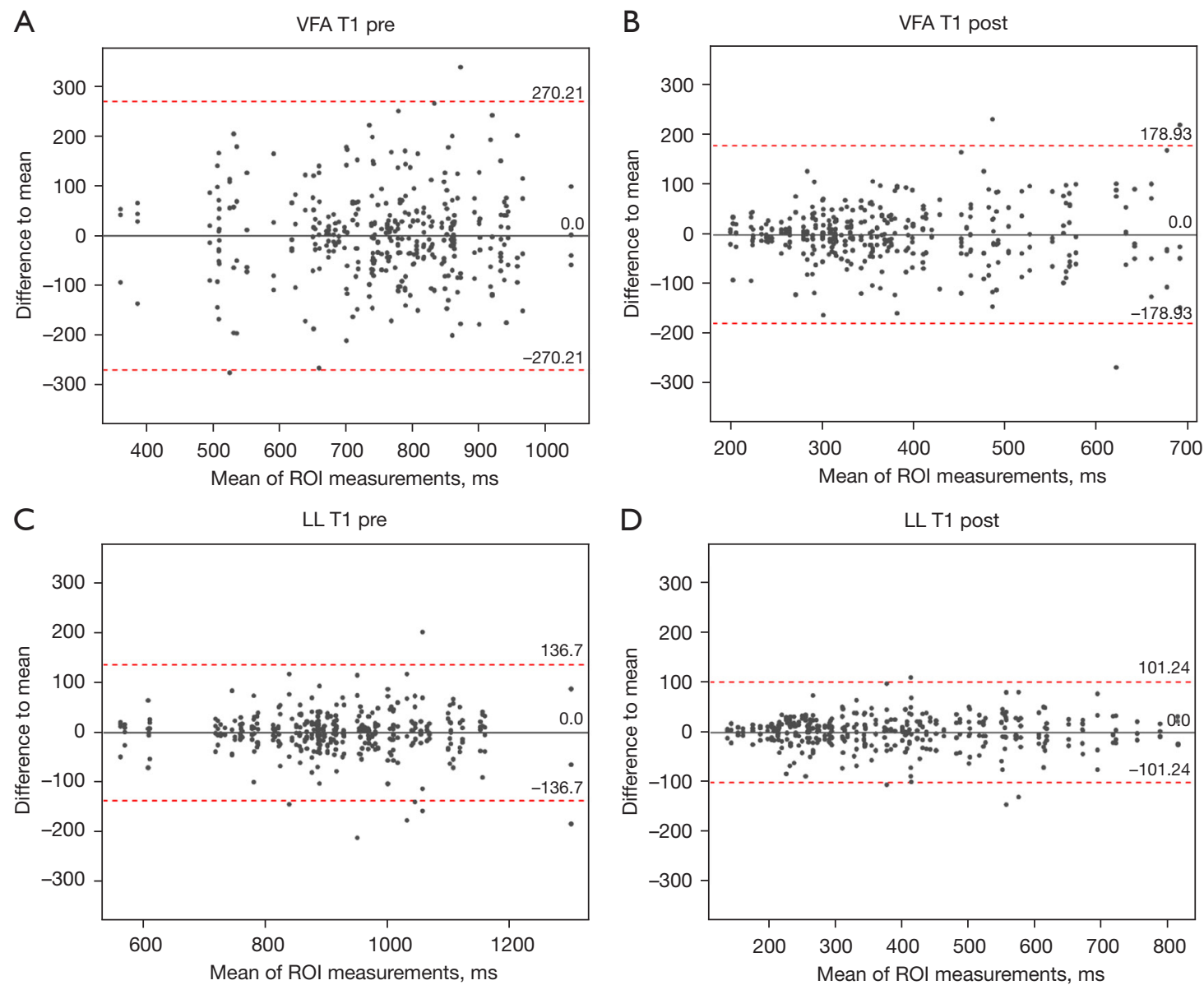

Figure 6 Comparison of homogeneity: Variable flip angle $v s$ Look-Locker T1 maps. Bland-Altman plots comparing variable-flip-angle (VFA) $\operatorname{VIBE}(A, B)$ and Look-Locker (LL; C,D) sequences before (A,C) and after (B,D) administration of Gd-EOB-DTPA. ROI measurement with LL sequence shows less variation to the mean value, indicating more homogenous ROI measurements using the Look-Locker technique.

information at the same time, offering a "one stop shot" approach (28). MRI is an ideal candidate for threedimensional determination of liver function, although the development of the suitable sequences and the parameters to be derived from the image information is still ongoing. In this study, we compared the data obtained from two different MR T1 relaxometry sequences in the context of a dynamic liver function test $\left({ }^{13} \mathrm{C}-\mathrm{MBT}\right)$.

For determination of liver function, assessed by ChildPugh classification, the use of a respective Look-Locker sequence has been published: Katsube et al. used a respective fitting tool (Philips Research Integrated Development Environment, PRIDE) based on a predecessor Look-Locker sequence (13), and Yoon et al. recently showed a modified Look-Locker inversion recovery sequence (MOLLI), which has been widely investigated in cardiac imaging (30).
Both of them were able to discriminate between different Child-Pugh classes. However, in this study, we present an advanced prototypical Look-Locker 2D FLASH sequence and make a comparison to a variable flip angle 3D VFA sequence.

The results of our study are consistent with Kim et al. who in their study compared look-locker inversion recovery and B1 inhomogeneity-corrected T1 mapping methods with variable flip angle for the assessment of liver function and prediction of liver failure as assessed by the Child-Pugh score (31). Compared to Kim et al., the ${ }^{13} \mathrm{C}$-methacetin breath test shows a more accurate prediction of current liver function (21).

In our study, both VFA- and LL-based calculated reduction rates of $\mathrm{T} 1$ relaxation time (rrT1) were able to differentiate between the three categories of liver function 
as determined by the ${ }^{13} \mathrm{C}$-methacetin breath test. The native T1 relaxation times before administration of Gd-EOBDTPA (T1 pre) were not able to discriminate between the three groups, irrespective of whether using VFA T1 pre or LL T1 pre. In our opinion, this affirms that T1 pre is up to now not a suitable factor to evaluate liver function. However, the use of pre-contrast T1 relaxometry for the assessment of several liver diseases is not entirely clear and contradictory in the literature: Regarding fatty liver, several animal studies describe reduction as well as prolongation of unenhanced $\mathrm{T} 1$ relaxation time $(32,33)$. For the characterization of fibrosis or cirrhosis, contrary results have been found as well $(6,13,34,35)$. Explanations for the varying effects observed in those studies are numerous. An important factor is the iron content of the liver. Further, the method of disease induction, mode of disease (acute or chronic), tissue inflammation, and necrosis are able to influence $\mathrm{T} 1$ relaxation time.

In our study, a simple linear regression analysis revealed that reduction rates of $\mathrm{T} 1$ relaxation times (VFA $\operatorname{rrT} 1$ $r=0.706, L L$ rrT1 $r=0.727)$ and LL T1 post ( $r=0.724)$ show a high correlation with liver function as determined by the ${ }^{13} \mathrm{C}-\mathrm{MBT}$. The T1 relaxation times after Gd-EOB-DTPA administration (T1 post) for T1 VFA also correlates with liver function, but to a lesser extent $(\mathrm{r}=0.590)$ compared to LL T1 post. Thus basically, both MR sequences can be used to assess liver function, with LL rrT1 being superior considering $\mathrm{T} 1$ post values only. The $\mathrm{T} 1 \mathrm{maps}$ acquired with the Look-Locker sequence are more homogenous than the ones acquired with the VFA sequence, before as well as after the administration of Gd-EOB-DTPA: This becomes obvious comparing the two mapping sequences regarding both the ICC, which was higher for LL (LL T1 pre $=0.88$, LL T1 post $=0.95$; VFA T1 pre $=0.58$, VFA T1 post $=0.75$ ) and CR, which was lower for LL (LL T1 pre, 137; VFA T1 pre, 270) and Gd-EOB-DTPA-enhanced T1 maps (LL T1 post, 101; VFA T1 post, 179). Reliable ROI placement is therefore much simpler in the LL-based images compared to the VFA-based images. Particularly in patients with ascites, this discrepancy becomes more evident. Figure 5 shows the exemplary images of a patient suffering from ascites. According to the ${ }^{13} \mathrm{C}-\mathrm{MBT}$ value of $120 \mu \mathrm{g} / \mathrm{kg} / \mathrm{h}$, this patient is grouped into category 3 with severely impaired liver function. Both MRI-derived reduction rates of $\mathrm{T} 1$ relaxation rates are low (VFA $\operatorname{rrT} 1=46 \%, \mathrm{LL}$ $\operatorname{rrT} 1=48 \%)$. Looking at the relaxation times per se, the LL sequences gives generally higher values than the VFA sequence (LL T1 pre $824.5 \mathrm{~ms}$, LL T1 post $430.5 \mathrm{~ms}$, VFA
T1 pre $531.0 \mathrm{~ms}$, VFA T1 post $288.8 \mathrm{~ms}$ ).

Moreover, the LL-based relaxation times before and after Gd-EOB-DTPA administration show less variation than those based on VFA T1 maps. This difference is also visible in the T1 maps themselves. In the presented ascitic patient, the LL-based T1 maps are clearly superior to the VFA-based maps. Especially in the native VFA map (Figure 5C), there is an area with inhomogeneity which impedes the placement of the ROIs and thereby the estimation of liver function. The variable-flip-angle sequence is more sensitive to $\mathrm{B} 1$ field inhomogeneities than the LL sequence. The additionally acquired B1 map helps improve image quality; however, it cannot wholly prevent B1 inhomogeneity effects. As about two-thirds of the patients included in this study $(62.5 \%, 60$ patients) suffer from liver cirrhosis, the use of Look-Locker sequences for T1 mapping appears to be beneficial in this aspect. The differences in homogeneity between both mapping sequences can be explained by the following facts: The signal model for VFA is based on FLASH. For TR smaller than T1 and small flip angles, which is very suited for typical protocols, the signal model depends only on the combination of squared flip angles times T1. Therefore-to determine T1-one needs to know the flip angle extremely well. This is a challenge in particular at $3 \mathrm{~T}$ and the $\mathrm{B} 1$ correction tries to address it to the best extend possible. In contrast the Look-Locker method as a much weaker flip angle dependence as T1 is mainly determined by the relaxation curve and not a steady state. The flip angle dependence only enters due to the continuous FLASH readouts and is addressed in the signal modelling. The drawbacks of VFA compared to inversion or saturation based techniques-even at $1.5 \mathrm{~T}$-are well demonstrated by Tirkes et al. (36).

Despite the visible advantages of the Look-Locker sequence, there are still some major limitations of this T1 mapping technique. In contrast to the $3 \mathrm{D}$ VFA, the current version of the 2D Look-Locker sequence only enables the acquisition of three slices within a single breathhold. Therefore, only a spatially limited depiction of the liver is possible. Imaging of the entire liver tissue should be the focus of further technical developments. Still, the Look-Locker-based sequence offers remarkable imaging possibilities. Furthermore, the combination of Look-Locker with water-fat separation may be advantages to disentangle changes in $\mathrm{T} 1$ for the water component from the fat content of the tissue.

The present study has some limitations. First, our study was a single-center study with a limited patient 
number and patient distribution, especially there was a low number of female patients with impaired liver function. A larger patient cohort and a prospective design would improve the statistical power of our analysis. Second, only one radiologist placed the ROIs. Due to parenchymal inhomogeneities, ROI placement could be a source of variation. However, this drawback should be minimized by using an average of 4 measurements across the liver.

In conclusion, both $\mathrm{T} 1$ relaxometry sequences enable the assessment of metabolic liver function, which is highly correlated with the gold standard ${ }^{13} \mathrm{C}-\mathrm{MBT}$. However, the Look-Locker sequence is more homogenous and less susceptible to artifacts and, therefore, more advantageous, especially in patients with impaired liver function and consecutive complications such as ascites. It offers radiologists a reliable insight into the liver function and especially in the assessment of remaining hepatic function after various interventions.

\section{Acknowledgments}

Funding: None.

\section{Footnote}

Reporting Checklist: The authors have completed the MDAR checklist. Available at https://qims.amegroups.com/article/ view/10.21037/qims-21-597/rc

Conflicts of Interest: All authors have completed the ICMJE uniform disclosure form (available at https://qims. amegroups.com/article/view/10.21037/qims-21-597/coif). $\mathrm{DN}$ is an employee of MR Applications Predevelopment, Siemens Healthineers, Erlangen, Germany. The other authors have no conflicts of interest to declare.

Ethical Statement: The authors are accountable for all aspects of the work in ensuring that questions related to the accuracy or integrity of any part of the work are appropriately investigated and resolved. The study was conducted in accordance with the Declaration of Helsinki (as revised in 2013). The study was approved by institutional ethics board of the University Hospital Regensburg (16101-0177) and informed consent was taken from all individual participants.

Open Access Statement: This is an Open Access article distributed in accordance with the Creative Commons
Attribution-NonCommercial-NoDerivs 4.0 International License (CC BY-NC-ND 4.0), which permits the noncommercial replication and distribution of the article with the strict proviso that no changes or edits are made and the original work is properly cited (including links to both the formal publication through the relevant DOI and the license). See: https://creativecommons.org/licenses/by-nc-nd/4.0/.

\section{References}

1. Hamm B, Staks T, Mühler A, Bollow M, Taupitz M, Frenzel T, Wolf KJ, Weinmann HJ, Lange L. Phase I clinical evaluation of Gd-EOB-DTPA as a hepatobiliary MR contrast agent: safety, pharmacokinetics, and MR imaging. Radiology 1995;195:785-92.

2. Hammerstingl R, Huppertz A, Breuer J, Balzer T, Blakeborough A, Carter R, et al. Diagnostic efficacy of gadoxetic acid (Primovist)-enhanced MRI and spiral CT for a therapeutic strategy: comparison with intraoperative and histopathologic findings in focal liver lesions. Eur Radiol 2008;18:457-67.

3. Haimerl M, Wächtler M, Platzek I, Müller-Wille R, Niessen C, Hoffstetter P, Schreyer AG, Stroszczynski C, Wiggermann P. Added value of Gd-EOB-DTPA-enhanced Hepatobiliary phase MR imaging in evaluation of focal solid hepatic lesions. BMC Med Imaging 2013;13:41.

4. Ryeom HK, Kim SH, Kim JY, Kim HJ, Lee JM, Chang YM, Kim YS, Kang DS. Quantitative evaluation of liver function with MRI Using Gd-EOB-DTPA. Korean J Radiol 2004;5:231-9.

5. Kamimura K, Fukukura Y, Yoneyama T, Takumi K, Tateyama A, Umanodan A, Shindo T, Kumagae Y, Ueno S, Koriyama C, Nakajo M. Quantitative evaluation of liver function with $\mathrm{T} 1$ relaxation time index on Gd-EOBDTPA-enhanced MRI: comparison with signal intensitybased indices. J Magn Reson Imaging 2014;40:884-9.

6. Haimerl M, Utpatel K, Verloh N, Zeman F, Fellner C, Nickel D, Teufel A, Fichtner-Feigl S, Evert M, Stroszczynski C, Wiggermann P. Gd-EOB-DTPAenhanced MR relaxometry for the detection and staging of liver fibrosis. Sci Rep 2017;7:41429.

7. Verloh N, Utpatel K, Haimerl M, Zeman F, Fellner C, Fichtner-Feigl S, Teufel A, Stroszczynski C, Evert M, Wiggermann P. Liver fibrosis and Gd-EOB-DTPAenhanced MRI: A histopathologic correlation. Sci Rep 2015;5:15408.

8. Leonhardt M, Keiser M, Oswald S, Kühn J, Jia J, Grube M, Kroemer HK, Siegmund W, Weitschies W. Hepatic uptake 
of the magnetic resonance imaging contrast agent $\mathrm{Gd}$ EOB-DTPA: role of human organic anion transporters. Drug Metab Dispos 2010;38:1024-8.

9. Nassif A, Jia J, Keiser M, Oswald S, Modess C, Nagel S, Weitschies W, Hosten N, Siegmund W, Kühn JP. Visualization of hepatic uptake transporter function in healthy subjects by using gadoxetic acid-enhanced MR imaging. Radiology 2012;264:741-50.

10. Reimer P, Schneider G, Schima W. Hepatobiliary contrast agents for contrast-enhanced MRI of the liver: properties, clinical development and applications. Eur Radiol 2004;14:559-78.

11. Haimerl M, Verloh N, Zeman F, Fellner C, Nickel D, Lang SA, Teufel A, Stroszczynski C, Wiggermann P. Gd-EOB-DTPA-enhanced MRI for evaluation of liver function: Comparison between signal-intensity-based indices and T1 relaxometry. Sci Rep 2017;7:43347.

12. Wright PJ, Mougin OE, Totman JJ, Peters AM, Brookes MJ, Coxon R, Morris PE, Clemence M, Francis ST, Bowtell RW, Gowland PA. Water proton T1 measurements in brain tissue at 7, 3, and 1.5 T using IREPI, IR-TSE, and MPRAGE: results and optimization. MAGMA 2008;21:121-30.

13. Katsube T, Okada M, Kumano S, Hori M, Imaoka I, Ishii K, Kudo M, Kitagaki H, Murakami T. Estimation of liver function using T1 mapping on Gd-EOB-DTPAenhanced magnetic resonance imaging. Invest Radiol 2011;46:277-83.

14. Heye T, Yang SR, Bock M, Brost S, Weigand K, Longerich T, Kauczor HU, Hosch W. MR relaxometry of the liver: significant elevation of T1 relaxation time in patients with liver cirrhosis. Eur Radiol 2012;22:1224-32.

15. Verloh N, Haimerl M, Zeman F, Schlabeck M, Barreiros A, Loss M, Schreyer AG, Stroszczynski C, Fellner C, Wiggermann P. Assessing liver function by liver enhancement during the hepatobiliary phase with GdEOB-DTPA-enhanced MRI at 3 Tesla. Eur Radiol 2014;24:1013-9.

16. Yoneyama T, Fukukura Y, Kamimura K, Takumi K, Umanodan A, Ueno S, Nakajo M. Efficacy of liver parenchymal enhancement and liver volume to standard liver volume ratio on Gd-EOB-DTPA-enhanced MRI for estimation of liver function. Eur Radiol 2014;24:857-65.

17. Haimerl M, Schlabeck M, Verloh N, Zeman F, Fellner C, Nickel D, Barreiros AP, Loss M, Stroszczynski C, Wiggermann P. Volume-assisted estimation of liver function based on Gd-EOB-DTPA-enhanced MR relaxometry. Eur Radiol 2016;26:1125-33.
18. Yoon JH, Lee JM, Kim E, Okuaki T, Han JK. Quantitative Liver Function Analysis: Volumetric T1 Mapping with Fast Multisection B1 Inhomogeneity Correction in Hepatocyte-specific Contrast-enhanced Liver MR Imaging. Radiology 2017;282:408-17.

19. Look DC, Locker DR. Time Saving in Measurement of NMR and EPR Relaxation Times. Rev Sci Instrum 1970;41:250-1.

20. Bojorquez JZ, Bricq S, Acquitter C, Brunotte F, Walker PM, Lalande A. What are normal relaxation times of tissues at 3 T? Magn Reson Imaging 2017;35:69-80.

21. Stockmann M, Lock JF, Riecke B, Heyne K, Martus P, Fricke M, Lehmann S, Niehues SM, Schwabe M, Lemke AJ, Neuhaus P. Prediction of postoperative outcome after hepatectomy with a new bedside test for maximal liver function capacity. Ann Surg 2009;250:119-25.

22. Stockmann M, Lock JF, Malinowski M, Seehofer D, Puhl G, Pratschke J, Neuhaus P. How to define initial poor graft function after liver transplantation? - a new functional definition by the LiMAx test. Transpl Int 2010;23:1023-32.

23. Chung S, Kim D, Breton E, Axel L. Rapid B1+ mapping using a preconditioning RF pulse with TurboFLASH readout. Magn Reson Med 2010;64:439-46.

24. Deoni SC, Rutt BK, Peters TM. Rapid combined T1 and T2 mapping using gradient recalled acquisition in the steady state. Magn Reson Med 2003;49:515-26.

25. Deichmann R, Haase A. Quantification of T1 values by SNAPSHOT-FLASH NMR imaging. J Magn Reson (1969) 1992;96:608-12.

26. Sakka SG. Assessing liver function. Curr Opin Crit Care 2007;13:207-14.

27. Morris-Stiff G, Gomez D, Prasad R. Quantitative assessment of hepatic function and its relevance to the liver surgeon. J Gastrointest Surg 2009;13:374-85.

28. Geisel D, Lüdemann L, Hamm B, Denecke T. ImagingBased Liver Function Tests--Past, Present and Future. Rofo 2015;187:863-71.

29. Bae KE, Kim SY, Lee SS, Kim KW, Won HJ, Shin YM, Kim PN, Lee MG. Assessment of hepatic function with Gd-EOB-DTPA-enhanced hepatic MRI. Dig Dis 2012;30:617-22.

30. Yoon JH, Lee JM, Paek M, Han JK, Choi BI. Quantitative assessment of hepatic function: modified look-locker inversion recovery (MOLLI) sequence for T1 mapping on Gd-EOB-DTPA-enhanced liver MR imaging. Eur Radiol 2016;26:1775-82.

31. Kim JE, Kim HO, Bae K, Choi DS, Nickel D. T1 
mapping for liver function evaluation in gadoxetic acidenhanced MR imaging: comparison of look-locker inversion recovery and B1 inhomogeneity-corrected variable flip angle method. Eur Radiol 2019;29:3584-94.

32. Chai JW, Lin YC, Chen JH, Wu CC, Lee CP, Chu WC, Lee SK. In vivo magnetic resonance (MR) study of fatty liver: importance of intracellular ultrastructural alteration for MR tissue parameters change. J Magn Reson Imaging 2001;14:35-41.

33. Jacobs DO, Trerotola SO, Settle RG, Rolandelli RH, Wolf GL, Rombeau JL. In vitro detection of fatty liver infiltration in protein-depleted rats using proton nuclear magnetic resonance. J Surg Res 1985;39:25-30.

Cite this article as: Verloh N, Fuhrmann I, Fellner C, Nickel D, Zeman F, Kandulski A, Hornung M, Stroszczynski C, Wiggermann P, Haimerl M. Quantitative analysis of liver function: 3D variable-flip-angle versus Look-Locker T1 relaxometry in hepatocyte-specific contrast-enhanced liver MRI. Quant Imaging Med Surg 2022;12(4):2509-2522. doi: 10.21037/qims-21-597
34. Stark DD, Bass NM, Moss AA, Bacon BR, McKerrow JH, Cann CE, Brito A, Goldberg HI. Nuclear magnetic resonance imaging of experimentally induced liver disease. Radiology 1983;148:743-51.

35. Chow AM, Gao DS, Fan SJ, Qiao Z, Lee FY, Yang J, Man $\mathrm{K}, \mathrm{Wu} \mathrm{EX}$. Measurement of liver $\mathrm{T}_{1}$ and $\mathrm{T}_{2}$ relaxation times in an experimental mouse model of liver fibrosis. J Magn Reson Imaging 2012;36:152-8.

36. Tirkes T, Zhao X, Lin C, Stuckey AJ, Li L, Giri S, Nickel D. Evaluation of variable flip angle, MOLLI, SASHA, and IR-SNAPSHOT pulse sequences for T1 relaxometry and extracellular volume imaging of the pancreas and liver.

MAGMA 2019;32:559-66. 